\title{
Editorial
}

\section{A importância do conhecimento científico no combate ao uso nocivo de tabaco, álcool e drogas ilícitas}

\section{The importance of scientific knowledge in combating the harmful effects of tobacco, alcohol, and illegal drugs}

\author{
Prof. Dr. Arthur Guerra de Andrade
}

Professor-associado do Departamento de Psiquiatria da Faculdade de Medicina da Universidade de São Paulo (FMUSP); professor titular da Faculdade de Medicina do ABC (FMABC).

O consumo indevido de drogas lícitas e ilícitas é um sério problema de saúde pública que atinge de forma preocupante todos os países do mundo. Estima-se que entre os anos de 2005 e 2006, aproximadamente 200 milhões de indivíduos tenham consumido drogas ilícitas, correspondendo a quase $5 \%$ da população mundial na faixa etária entre 15 e 64 anos. Neste cenário, as drogas mais consumidas são: maconha, anfetaminas, opiáceos e cocaína. Em relação às substâncias lícitas, a situação não é menos preocupante: o consumo prejudicial de álcool é responsável por quase 4\% de todas as mortes no mundo, sendo a principal causa de morte e invalidez nos países em desenvolvimento que apresentam baixa taxa de mortalidade e o terceiro principal fator de risco para a saúde, após o tabaco e a hipertensão arterial sistêmica, em países em desenvolvimento. No mundo há, por sua vez, 1,3 bilhão de indivíduos que utilizam tabaco e essa substância responde por 4,1\% da carga global de doenças, segundo a Organização Mundial da Saúde (OMS).

Além de enfermidades e mortes, o consumo de drogas associa-se a uma série de problemas psicológicos e sociais, estando os jovens situados no grupo de maior risco para o uso experimental e possível abuso de substâncias, especialmente o álcool, o tabaco e a maconha. Entre as possíveis consequiências negativas, podemos mencionar desintegração familiar, depressão, violência e acidentes de trânsito.

Diante desse quadro, é fundamental o investimento no tripé prevenção (educação), controle (fiscalização) e tratamento. Ainda, todas as ações devem estar embasadas em evidências científicas que poderão auxiliar na compreensão da prevalência dos problemas causados pelo uso indevido de substâncias e contribuirão para a identificação das melhores estratégias de prevenção e tratamento. Nessa direção, cabe salientar a importância da formação acadêmica dos diferentes profissionais que atuam nesse campo de conhecimento com o objetivo de enriquecer o debate e formar pesquisadores que possam atuar em suas áreas a partir do peso das evidências.

Este suplemento da Revista de Psiquiatria Clínica é fruto da produção de alunos de pós-graduação de diversos departamentos da Universidade de São Paulo que participaram da disciplina "Álcool e Drogas: Atualização em Metodologia de Pesquisa” do Departamento de Psiquiatria da Faculdade de Medicina da Universidade de São Paulo (FMUSP). A riqueza dos temas explorados é proporcional à diversidade encontrada no campo das adições, incluindo artigos sobre os custos dos problemas causados pelo abuso de álcool, comorbidade entre dependência de álcool e drogas e outros transtornos psiquiátricos, epidemiologia do beber "pesado" no Brasil, efeitos do uso e abuso de álcool e drogas em populações específicas, como adolescentes, mulheres grávidas, estudantes universitários, entre outros.

Espera-se, assim, que a universidade esteja cumprindo seu papel de formar bons pesquisadores e que estes, por sua vez, estejam levando a outros profissionais da área da saúde e à sociedade como um todo o que há de mais recente na literatura científica sobre o tema em questão. 